DOI: $10.20472 / T E .2015 .3 .2 .003$

\title{
FUTURE HEALTH CARE MANAGERS AND THE NEED FOR AN INTERNATIONAL AND INTERPROFESSIONAL LEARNING EXPERIENCE - THE CASE OF A SUMMER SCHOOL ON CROSS-BORDER HEALTH CARE
}

\author{
HERMANN SINZ, JOHANNA KOSTENZER, SIEGFRIED WALCH
}

\begin{abstract}
:
Internationalisation and interprofessional cooperation are central to health care in the 21st century. For health care managers, policy analysts and academic researchers, knowledge of multiple relevant disciplines and an international view and network are key to understanding and solving the challenges that health care systems and health care services are facing. One of the primary challenges for health care managers in both private and public organizations will be the adaption to a continuously changing environment driven by technological development, demographic transitions and legal evolution.

A recent development in this context has been the EU directive on the application of patients' rights in cross-border health care, which had to be implemented by all member states by October 2013, and allows individuals to receive treatment in other member states if they also have the right to this treatment in their home country. This increase in the mobility of patients and services also requires health care managers to be equipped with specialized knowledge and technical skills in order to address the international dimension (e.g. legal and financial issues) and to enable high quality of work by considering the diverse cultural and professional backgrounds of staff members.

In order to explain how future health care managers can be prepared for this interprofessional and intercultural work environment, the article focuses on two main aspects. First, it sheds light on the core competencies required and explains how those skills can be acquired and further developed. Second, based on the example of an international summer school on cross border health care this article illustrates how interprofessional and intercultural learning can be promoted in the course of a two-week intensive program. The summer school which took place in 2013 and 2014 was jointly organized by four European universities (University of Bologna, University of Oslo, Erasmus University Rotterdam and Management Center Innsbruck). The concept will be outlined in detail to give insight to a practical example on how to promote intercultural and interprofessional learning among an international group of health care management students.
\end{abstract}

\section{Keywords:}

health care management education, cross border health care, European patient mobility, intercultural learning, team development, leadership skills, interprofessional education, Internationalization

JEL Classification: 110,123, M10

\section{Authors:}

HERMANN SINZ, MCI Management Center Innsbruck, Austria, Email: hermann.sinz@mci.edu 
JOHANNA KOSTENZER, MCI Management Center Innsbruck, Austria, Email: johanna.kostenzer@mci.edu

SIEGFRIED WALCH, MCI Management Center Innsbruck, Austria, Email: siegfried.walch@mci.edu

\section{Citation:}

HERMANN SINZ, JOHANNA KOSTENZER, SIEGFRIED WALCH (2015). Future health care managers and the need for an international and interprofessional learning experience - the case of a summer school on cross-border health care. International Journal of Teaching and Education, Vol. III(2), pp. 31-49., 10.20472/TE.2015.3.2.003 


\section{Background}

Health care systems in Europe and worldwide will undergo changes due to population aging, increasing prevalence of chronic diseases and technological innovation (Kleinert and Horton, 2013). Anticipating future skills for professionals working in the sector to meet new health care demands is a challenge for European Union (EU) member states. They need to act swiftly to avoid skills mismatches and gaps to ensure tomorrow's workforce is equipped with the right skills. Due to increasing scarcity of resources devoted to welfare program (Karanikolos et al., 2013) economic competencies, managerial skills and expertise in how health care organizations and networks are managed are going to be progressively more demanded especially among providers' organizations (Mahon and Young, 2005.). One of the primary challenges for health care managers in both private and public organizations will be the adaption to a continuously changing environment driven by technological development, demographic transitions and legal evolution.

One recent development in this context has been the EU directive on the application of patients' rights in cross-border health care, which had to be implemented by all member states by October 2013, and allows individuals to receive treatment in other member states if they also have the right to this treatment in their home country (European Commission, 2011). The health insurance covering the patient's treatment costs must compensate up to the amount which it would have reimbursed for the same treatment in the home country. From a patient's perspective the directive offers several opportunities, such as shorter waiting times, perceived higher quality of treatment, lower co-payments or increased competition between health care providers in the home country leading to lower costs and higher quality. However, the directive might also be a challenge for national health care systems, e.g. undermining national systems of treatment allocation as in the case of waiting lists (Kifmann and Wagner, 2014). It is expected that the EU directive on the application of patients' rights in cross-border health care further drives mobility and creates new conditions for all stakeholders involved (European Commission, 2011). This increased interconnectedness in health care raises many policy issues including access and quality in crossborder services, information requirements for citizens, providers and other stakeholders, the potential for cooperation in the health and social field, and the reconciliation of national policies with European obligations. Increased mobility of patients and services also requires health care managers to be equipped with specialized knowledge and technical skills in order to address the international dimension (e.g. legal and financial issues) and to enable high quality of work by considering the diverse cultural and professional backgrounds of staff members.

In order to explain how future health care managers can be prepared for this interprofessional and intercultural work environment, the article focuses on two main aspects. First, it sheds light on the core competencies required and explains how those skills can be acquired and further developed. Second, based on the example of an international summer school on cross border health care this article illustrates how interprofessional and intercultural learning can be promoted in the course of a two-week intensive program. The summer school which took place in 2013 and 2014 was jointly organized by four European universities (University of Bologna, University of Oslo, Erasmus University Rotterdam and Management Center Innsbruck). The concept will be outlined in detail to give insight to a practical example on how to promote intercultural and interprofessional learning among an international group of health care management students. 


\section{Skills and Competencies needed by Health Care Managers - are Soft Skills the new Hard Skills?}

In the modern world of work, and in particular in the rapidly changing health care environment, the concept of traditional job descriptions defined as a fixed set of roles and responsibilities is increasingly being replaced by a more general description of a position permitting greater flexibility and adaption to changes in the organizational context (Garman and Johnson, 2006). A foundational knowledge base which is jutted out by critical behavioral and technical skill sets is argued to be vital for optimal individual and organizational performance (Calhoun et al., 2008). Therefore technical knowledge alone might no longer be a major differentiator concerning performance but expected to be a baseline competence across graduates from various programs in health care management and administration (Karoly and Panis, 2004).

The contemporary management literature repeatedly provides examples of universal skills for high job performance or leadership such as team building (Clements et al., 2007), talent development (Ulrich and Smallwood, 2004), process improvement (Matta and Ashkenas, 2003) or collaboration (Wass et al., 2001). Moreover, the importance of emotional intelligence competencies (Freshman and Rubino, 2002; Goleman, 2000) and soft skills in management are increasingly recognized as a key factor for optimal performance in the field (Calhoun et al., 2008)

When looking into scientific literature to find most important competencies for health care managers, many studies can be found ranking soft skills as particularly important. For example, a study conducted by a consortium of six professional health care associations in the United States (Stefl, 2008) using the research from and experience with their individual credentialing process found that communication and relationship management, leadership, professionalism, knowledge of the health care environment as well as business skills and knowledge (including the understanding of organizational and interprofessional dynamics) were found to be the five major competency domains An older review of a series of Delphi studies among health care executives (Hudak et al., 2000) shows similar findings with listening skills and communication, leadership, human relations, conflict management and understanding of the motives of different professional groups as the most essential abilities. A study by MacKinnon et al. (2004) among 485 Canadian health service managers and executives confirms this by showing that all of the top-five-rated competencies were categorized under the dimension of leadership and communication (teambuilding, listening, flexibility in effectively managing change, verbal communication, and commitment to consumers).

Although several studies reveal teamwork to be an essential component in the provision of high quality and safe patient care (Berwick, 2002; Ferlie and Shortell, 2001; West et al., 2002) few studies on how to develop effective team-members and good teamwork skills in health care management education can be found. Many undergraduate and postgraduate programs for health professionals offer little formal training in the development of teamwork skills and leave this competence area to training "on-the-job" (Wake-Dyster, 2001). Moreover, the factors influencing effective teamwork in health care settings might differ between management and clinical teams (Leggat, 2007). For health service managers the most important competencies for effective team performance are leadership, respect for others, knowledge of organizational goals and strategies 
and the commitment to working collaboratively, as has been reported in the study by Leggat (2007). These findings are supported by previous studies showing that teams which encourage high levels of participation toward clear goals (Knight et al., 2001; Sparks and Schenk, 2001) combined with a climate of psychological safety (Edmondson, 1999; Edmondson et al., 2001) show better overall team performance (Edmondson et al., 2001; Yeatts and Seward, 2000). One could argue from those findings that in the education of health care managers more weight should be put on the development of teamwork and leadership skills. In addition to that, a critical reflection of the traditional training and socialization of health professionals - having its focus on individual skills, achievement and accountability (Leggat, 2007) and often supported by health care systems rewarding individual and discipline specific behavior (Farmer et al., 2002) - might be required.

In the context of the challenges mentioned above and in order to cope with complex needs and tasks in health care the strengthening of the coordination of health care services, particularly interprofessional cooperation and the mutual understanding of the various involved professional groups for the skills of their counterparts is increasingly seen as vital (Pruitt and Epping-Jordan, 2005; WHO, 2010). Although recommendations for interprofessional learning and education have been developed by various expert groups (Frenk et al., 2010; WHO, 2005, 2010), often the terms interdisciplinary, interprofessional, trans- or multiprofessional are used synonymously (Chamberlain-Salaun et al., 2013; Mahler et al., 2014; Mccallin, 2001) with the prefixes multi-, inter and trans referring to the nature or intensity of the collaboration (Mahler et al., 2014). In addition to that, definitions of what professions to include within the term "health professionals" vary within the academic literature. Building up on recent discussions (Careum, 2013; Frenk et al., 2010), in this paper a broad definition is applied including not only traditional professions such as physicians, nurses or therapists but also those health professionals named by the World Health Organisation (WHO) as 'enablers' (WHO, 2005) which refer to health economists, managers, and public health professionals.

Interprofessional education has been defined as 'members or students of two or more professions associated with health or social care, engaged in learning with, from and about each other' (Barr et al., 2005; Craddock et al., 2006). It focusses on the ability to share knowledge and skills between professions and contributes to a better understanding for the roles of other healthcare professionals (Bridges et al., 2011; Craddock et al., 2006). In recent years various organizations such as CAIPE ${ }^{1}$ or EIPEN ${ }^{2}$ were established to strengthen and promote this interprofessional approach in education of health professionals. Also WHO itself has published a framework for action on the topic (WHO, 2010). Moreover review studies (Reeves et al., 2008; Reeves et al., 2013) indicate that interprofessional education can have a positive impact on health care outcomes such as patient satisfaction and collaborative team behavior. Also a recent report by a global independent commission on "Education of Health Care Professionals for the 21st Century" published in the Lancet (Frenk et al., 2010) emphasizes the importance of interprofessional and especially also transprofessional education for health system performance. As actual practice in increasingly complex health settings is based on teams, in particular the teamwork of professionals with managers and administrators, leaders of the local community and policy makers might be of even

${ }^{1}$ CAIPE - Centre fo the advancement of Interprofessional Education www.caipe.org

${ }^{2}$ EIPEN - European Interprofessional Education Network www.eipen.org 
greater importance in the future. Therefore it might be vital to include competencies for teamwork in the educational experience of future professionals working in health care. The approach suggested in the Lancet report has been actively supported for dissemination and discussion in German speaking nations by the Swiss Careum Foundation. In its latest report (Careum, 2013) it proposes new approaches to interprofessional education that move beyond a focus on patient care to include also other critical functions of the health system.

Figure 1: The four required functional areas of a health care system

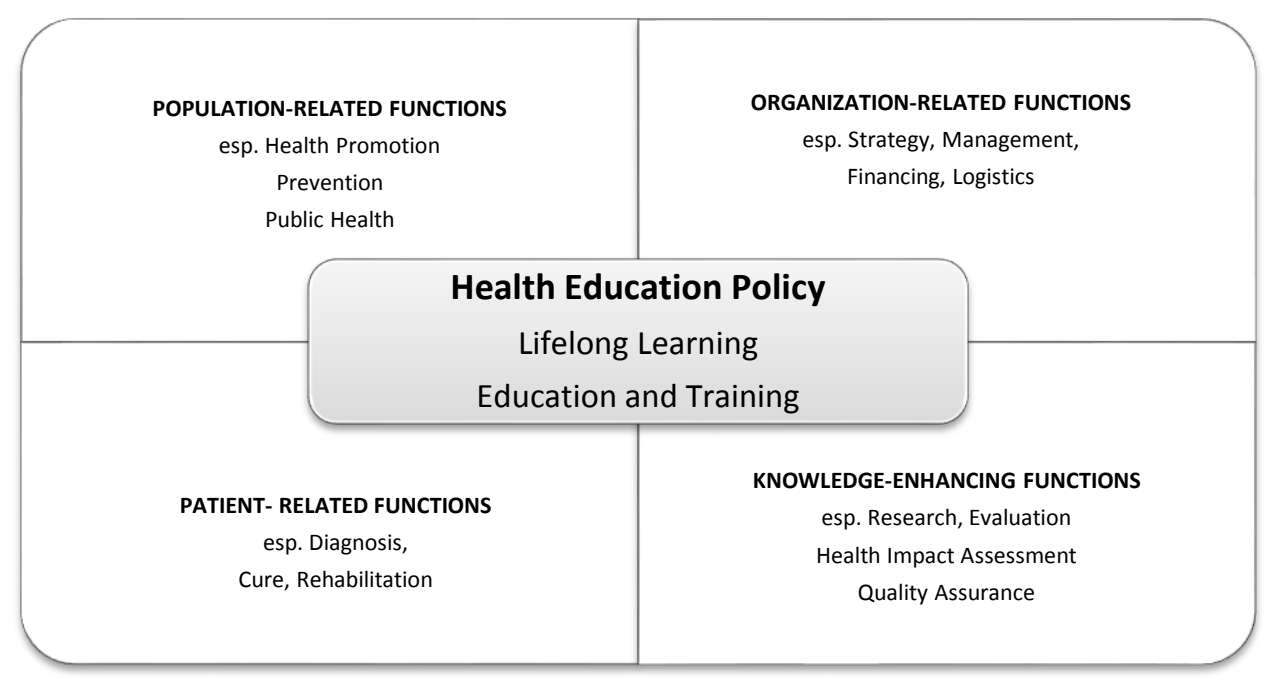

(Source: Careum, 2013)

As illustrated in the Careum approach (see Fig. 1), in order for a health system to efficiently and sustainably function, it must include professions dealing not only with care and cure but also with population-, organization- and knowledge enhancing aspects. Privileging patient-related functions might debase other professions and result in system errors, because an effective health care system in the wide spectrum between health promotion, public health, prevention, cure, rehabilitation, palliative care and social services does not only require "disease-related" professions. The cooperation of various health professionals thinking across disciplines and involving the patient, stakeholders and the environment, should be at the forefront.

\section{Internationalization in health care management education - the example of cross border health care}

At the latest since the Bologna declaration (European Commission, 1999) the terms "Internationality" and "Internationalization" have become buzz words in higher education and are often used synonymously. According to the Centre for Higher Education Development (CHE) "internationality refers either to an institution's current status or the status observable at the data acquisition with regard to international activities" while "internationalization describes a direction in which an institution is moving, through a more or less managed process from an actual status of 
internationality at time $\mathrm{X}$ towards a modified actual status of increased internationality at time $\mathrm{X}+\mathrm{n}$ " (Brandenburg and Federkeil, 2007). According to Knight (2008), internationalization in higher education can either be campus based or takes place abroad. The former refers primarily to the development of a curriculum which enables students to perform on a global level whereas the latter refers to cross-border activities in the form of student or staff exchange, international research and practice projects and the like. Ideally, a comprehensive internationalization strategy should interlink both aspects. Many (if not all) institutions in higher education are aware of this trend towards internationalization and have implemented a variety of measures. Also with English being the main teaching language of a rising number of study programs, international activities are becoming easier to realize. Increasing mobility, competition, and commercialization are further contributing towards the transformation of internationalization from being a strategic tool to a mainstream activity (de Wit, 2011).

Internationalization can be seen as a powerful opportunity for higher education in general and for future health care management professionals in particular. Across the European Union, health and social systems and related policies are becoming more interconnected than ever before. The spreading of diseases does not stop at borders; and neither do patients, staff, or technology. Although the vast majority of patients receive health care in their home country, sometimes the required treatment is best provided abroad. This can be the case for example for highly specialized care or in border areas where the nearest facility is located abroad. In such cases the term "crossborder health care" is being used. Cross-border health care is a growing phenomenon in the European Union and else. When in need of medical treatment, patients increasingly act as informed consumers who claim the right to choose their own providers, including those beyond borders (Wismar et al., 2011a).

This increasing mobility of people and services requires future health care managers to understand cultural differences and to react to trends in the global health care arena. Intercultural learning, mobility options and a close interaction with practice and research is therefore essential as well as a quantitative and qualitative evaluation of the achievement of previously defined goals of internationalization (Aerden et al., 2013). Against this background an educational concept on how to prepare future health care managers for the performance in this vastly changing and increasingly diverse environment has been developed and is illustrated in the following section.

\section{A Summer School on Cross Border Health Care}

The summer school EUROPAMO (European Patient Mobility on the example of health care services for tourists in the Veneto region) was organized jointly between four European universitylevel institutions and the local health care authorities of the Italian Veneto region. It took place for the first time in June 2013 and was again organized in 2014. Providing plenty of space for training of social skills as well as integrating interprofessional and international aspects has been of particular importance in the design of the two week intensive program. Therefore the organizers chose a problem-based learning approach (Wood, 2003) with a strong emphasis on multidisciplinary, multicultural and group-related aspects. The majority of the costs of the summer school were covered by the "European Intensive Program" of the European Commission. The participating universities provided additional funding. 
Overall, the summer school aimed at letting students with distinct health care backgrounds acquire a better understanding and respect across disciplinary, cultural and national borders. Derived from this central aim the learning objectives of the summer school were the following. After a successful completion of the program each student should be able:

- to develop an advanced understanding on determinants of the scope and policy of crossborder care within the European Union,

- to reflect on interprofessional and international aspects in cross-border health care and his/her working behavior in multinational and multidisciplinary working groups and,

- to develop overall (and in particular social) skills which are of high relevance for the scientific and professional practice (concept development, cooperation in teams, discussion and negotiation skills, presenting their analysis to stakeholders with different backgrounds and reflecting interdisciplinary interfaces between different healthcare disciplines).

In order to prepare for the summer school and to have an overview of the planned activities, the students received a detailed course book. This course book provided a schedule and content overview of the seminars, excursions and assignments and was distributed well in advance.

\section{Participants}

The summer school was jointly organized by University of Bologna (Italy), University of Oslo (Norway), Erasmus University Rotterdam (The Netherlands) and Management Center Innsbruck (Austria) which was serving as the project coordinating institution. The project was further supported by the Office for International Relations on behalf of the Verona Health Authority n. 20 of the Veneto Region (Italy) where the summer school took place. The main responsibility of the local authority was to arrange on-site visits with local and regional health care institutions and to connect with experts and provide facilities for the realization of the summer school. Each institution invited up to four lecturers and up to 10 students.

\subsection{Students}

The application and selection procedure for participating in the summer school was jointly designed by the four organizing partners. The application process (including interviews in English and a motivation dossier) was conducted at each of the partner institutions. Grades were not the topmost criteria - the main decisive factors were open-mindedness, creativity, motivation, social skills and attitude of the student. Moreover, reaching a balance between female and male students was aimed at. 40 master degree students were finally selected. The average age was 25.7 years (27.7 years. in 2013), 16 participants were male (13 participants in 2013), 24 female (27 participants in 2013) and the diverse group of students consisted of 13 different nationalities (19 in 2013). All of the participants were enrolled in a postgraduate program in the field of health care management, health policy or health economics at one of the universities involved. Moreover, the participating students brought in various areas of expertise from their undergraduate studies such as medicine, public health, epidemiology, economics, management, social work, sociology, psychology or nursing. 
In order to work on the team-based assignment eight student teams were created comprising of five students each. The allocation of students into teams took place on the first day and was the responsibility of the involved lecturers. The underlying aim of the group composition was to equally distribute students from the different universities and to spread the students as widely as possible across the various disciplines. Through this way of allocating team members the individual contribution of the respective members should be maximized (Maskell and Grabau, 1998).

\subsection{Academic Lecturers}

Overall 11 lecturers from the partnering universities participated at the summer school (10 lecturers in 2013). The lecturers were coming from various academic fields such as health economics, law, political science, medicine, business administration/management, health psychology, sociology and public health. Additionally to selecting students, the lecturers were also responsible for developing the summer school program and deciding upon the pedagogical approach. A close communication including online conferences between lecturers in the preparatory phase was vital for this purpose. Before the summer school started the lecturers were furthermore in charge of supervising and coaching the participating students for their preparatory work at home. Lecturers were also involved in coaching the teams during the summer school, in ensuring that the outcome of the summer school is transferred into the curriculum and the regular courses of the students at home and in contributing a lecture on a topic related to cross border care. The topics addressed through a lecture during summer school were focusing on the following thematic areas: patient mobility, medical tourism, reimbursement and cooperation with insurance companies, quality of care, European legal framework, pharmaceutical aspects and prescriptions, the Italian health care system, sustainable development and trade in health care services. Finally, the lecturers were involved in the evaluation of the quality of the activities during summer school.

\subsection{Health care Professionals and Industrial Experts}

The involvement of local hospitals, health insurance and topic-related IT companies provided impulses for increasing cooperation between health care management education and enterprises. Moreover, different health care professionals involved in providing services in the region (medical doctors, paramedics, pharmacists, psychologists, social workers, nurses, physiotherapists, managers and administrators) gave insight into their interprofessional working environment. Topics covered by health care professionals and industrial experts were specific agreements with health insurance companies abroad, e-billing for health services, e-health applications within the region and safe treatment in the area of spa treatment, wellness and fitness. Moreover the involved health care professionals and experts also took an active part in guiding the students in the work on their assignment by providing feedback.

\section{$6 \quad$ Learning Environment}

\subsection{Location}

The summer school took place in the Italian Red Cross Training Center in Jesolo Lido which is part of the Italian Veneto Region. The Veneto Region has always been an important strategic 
geographical location at the crossroads of Europe. It has a population of 4.8 million and has become a major tourist destination, which increases the number of people in the region dramatically twice a year during the peak summer and winter seasons. Consequently, Veneto makes for a very interesting case study of patient mobility and health tourism in Europe as the significant flow of tourists creates demanding conditions for regional service providers to cope with (Scaramagli et al., 2006).

\subsection{Learning space}

From an educational perspective we believe that having easy access to lecturers, experts, peers and online resources during the summer school is a key factor for fruitful learning. As the facilities also provided accommodation for students and lecturers a good structure for team-oriented activities and exchange of thoughts between the participants could be provided. The working space consisted of an auditorium which was used for lectures and seminars and could be adapted for small group work. Moreover the red-cross training center is surrounded by a park comprising also structures for group work as for example tables and benches. The learning space hence provided a quiet and private setting which is advantageous for discussing the progress of the assignment with the respective teams as well as team-related and personal issues. By offering this kind of learning space students were able to get explicit and direct forms of information and feedback and easy access to coaching by lecturers and experts. The set-up which assured a balance between the teams' privacy and overall room openness allowed for competitive work but still assured the group experience for the summer school participants.

\section{Summer School Program}

\subsection{Main Characteristics}

The teaching concept behind the summer school was characterized by the integration of different modes of delivery, models of instruction and styles of learning taking into account the fact that students learn by means of interaction, experimentation and reflective observation, albeit in varying levels of intensity (Cassidy, 2004). Such blended learning provides room for flexibility towards adapting to students' learning-style preferences, which in turn should support high academic achievement and motivation in their studies. Lectures were designed to be supplemented by project work, e-learning, self-study, case studies and problem-based learning (Wood, 2003). The summer school therefore provided an innovative learning design in the sense that learning did not take place in the conventional classroom environment but with substantial portions of exposure to a real health care setting with a problem-based learning approach in a multicultural, multidisciplinary and multifaceted manner.

For all participating institutions the increase of international mobility activities and implementing the European dimension in their curriculum has a high priority. The summer school was tied in with existing teaching programs in different ways as the single programs have a different approach towards health sciences and health management. So far, none of the different partners offers a special course on patient mobility and cross border care within the European Union. Therefore the summer school gave students as well as lecturers a rich and detailed cross-European analysis of 
different dimensions that determine the scope and policy of cross-border care (such as access to health care, benefits and tariffs, quality and safety, patients' rights, cross-border collaboration and cross-border health care data). For all students involved, the intercultural experiences and the interdisciplinary work have been a valuable experience and supplement to their own study program at home.

\subsection{Assignments}

The participating students had to work on two assignments, one individual assignment which was given to them in the pre-phase of the summer school and one team-based assignment which was a main element of the event. The individual assignment consisted of participating in an online webinar given by a former representative of the European commission (DG SANCO) on the topic of cross border care and afterwards writing an essay on the following question: "In the light of recent events such as the financial crisis and developments such as the cross border care directive, how has the balance of power for health and health care between the national and EU level changed, and how is it likely to change in the future? Give examples to support your argument".

The team-based assignment was developed based on a problem-centered and experiential learning approach (Kolb and Kolb, 2005). Groups were instructed to build a team representing Jesolo County in negotiations with a delegation of a fictitious EU member state called "Pandora". A bilateral agreement in the area of mobility of patients with chronic diseases had to be developed and presented in a role-play on the last day to an official delegation of Pandora republic (played by involved lecturers). The bilateral agreement was required to contain information on budget, planned activities, health management of hospital beds for foreign patients, exchanges of health care professionals, collaborations with local political authorities and the tourism sector as well as the use of information and communication technologies for the follow-up of patients. By organizing the assignments in such a way, students' technical skills (health economics, health care management, health policy, health services research, etc.) and particularly soft skills (negotiation, leadership, communication, etc.) could be further developed.

The assignments were graded based on the European Credit Transfer System scale (ECTS; European Commission, 2009). Using the ECTS scale allowed for a comparison with the grading scales of the involved national grading schemes and allowed students to acknowledge the ECTS gained for the summer school at their home universities. The individual assignment was counting $50 \%$ towards the final grade and graded based on the criteria 'clear argument and proper structure $(50 \%)$ ', 'examples given (30\%)' and language and presentation (20\%)'. The team based assignment was weighing $40 \%$ towards the final grade and has been evaluated by the lecturers $(80 \%)$ as well as through a peer grading $(20 \%)$. Lecturers based their grades on the criteria 'key issues identified and analyzed', 'quality of the proposal', 'implementation', 'presentation form and style' and 'handling of questions'. For the peer grading students were asked to give their peer groups a comment on what they learned from the respective presentation, provide suggestions for improvements and define a grade according to the ECTS grading scale. Finally, for the remaining $10 \%$ of the grade the attendance during two-week program was taken into account using attendance lists. 


\subsection{Schedule}

The two week program was divided into two stages during which the students had to work on different tasks in order to develop an applicable and sustainable outline of the bilateral agreement. Learning was realized in multinational and interprofessional workgroups guided by a lecturer and supervised by a main facilitator (the medical director of the local health authority of the Veneto region) being actively involved from the very start to the end of the summer school. After having done the preparatory reading in the home countries and participating in the online webinar on cross border health care (in which students were given the assignment to write an essay in the context of the cross border health care directive), the actual work in the summer school started one the first day with lectures providing an overview on the topic from different perspectives and identifying the tasks for the team-based assignment. On day two, three and four students were exposed to different health care facilities of the region (primary health care center, emergency service center for tourists, rehabilitation center, hospital with seasonal tourist services) in combination with presentations by health care professionals working on site. Additionally on each of those days reflective sessions with a focus on creativity, teamwork skills, presentation skills and critical thinking took place which was guided by a lecturer. Stage two (which took place in week two) was characterized by presentations given by faculty members of the involved universities which took place in the mornings. The input should help students in building up their knowledge base and theoretical framework in developing their bilateral agreements and focused on topics such as the cross border health care directive, economic issues behind patient mobility and best practice experiences from different European countries. The afternoons of week two had a focus on the coaching of the team processes but also offered students the possibility to take part in "mock" job interviews with health care executives via Skype. The coaching sessions were also used to prepare students for those interviews and to give them feedback afterwards. On the last day each team had to present their results in front of a simulated foreign delegation of politicians and representatives of public insurances.

In order to build social links among all participants of the summer school the program also included time for social events. These took place during the evening hours and during the weekend.

\section{Evaluation and Lessons Learnt}

The summer school has been evaluated by the participating students through a final questionnaire which was distributed to them on the final day. The questions given to students were grouped into the categories (1) Identification data and motivation, (2) Information and support, (3) Organization of the summer school, (4) Contents of the summer school, (5) Social events and have been rated on a scale of 1 (unsatisfactory) to 5 (excellent).

The results on identifying the main motivational factors for students' participation revealed that the three most highly ranked factors were to gain European experience (Mean value=4.2), a potential career benefit (by improving social skills) (Mean value=4.1) and the intercultural focus (Mean value=3.6). Concerning information and support students rated the support they received from their home (Mean value=3.85) and the host institution (Mean value=3.6) before and during the summer 
school as very good. Overall satisfaction with the organization of the summer school (infrastructure and accommodation) was rated as very high (Mean value=4.29). Pertaining to students' satisfaction with the contents of the summer school they judged the achievement of the academic learning outcomes (Mean value=3.8) and personal learning outcomes (Mean value=4.3) as very good. Concerning their satisfaction with the academic activities and the pedagogical aspects $74 \%$ rated the achievement of the expected learning outcomes as excellent or good, the overall quality of teaching was assessed as excellent or good by $72 \%$ of the students, and the number of hours spent was evaluated as excellent or good by $82 \%$ of the participants. Social events and activities in addition to the general course were rated as excellent or good by $95 \%$ of the participants. On a scale of 1 (not at all) to 5 (very much) the majority of the students rated the summer school as very beneficial for their later career (Mean value $=4.36$ ) or in finding a job in general (Mean value=3.92). The final evaluation showed that $95 \%$ of the 40 participating students evaluated the summer school as either excellent or good (Mean value=4.2).

\section{Discussion}

Health care educators take on a great part of the responsibility to prepare future health care managers to cope with a fast changing environment. In the industrial world health care systems are encountered with challenges such as demographic changes, coordination of service providers, technological innovation, costs and quality (Busse and Schlette, 2004; OECD, 2014; Rosenbrock and Gerlinger, 2012). In such a setting it is vital to identify the essential management competencies and incorporate them into and across all educational, training and curricular activities for the profession (Hudak et al., 2000).

The summer school on cross-border health care described in this article provides an example on how teamwork and leadership skills can be developed and tackles in particular two aspects which have been identified as becoming increasingly important in the education of future health care managers: first the international dimension, and second the cooperation of different professions.

In practice, the work in the field of health care requires close cooperation and communication. The more educational activities offer possibilities to develop such competencies, the better future health managers will be prepared for a workplace environment where teamwork is an essential component. One approach to train students for effective, collaborative work within a group is through team based learning. Interprofessional education can be characterized by students with two or more educational backgrounds working together and learning about each other's role by working on a common goal (Frenk et al., 2010). Although team-based learning has been a common instructional tool in non-medical settings, it has only been recently proposed in the education of health professionals (Haidet et al., 2002). Despite the simplicity of the approach its implementation might not be that easy. A large numbers of students and lacking facilities drive many instructors to a primarily lecture-based learning method (Xu et al., 2010). Moreover, the training and socialization of health professionals might restrict opportunities for collaboration as it still traditionally emphasizes individual skills, achievement and accountability (Farmer et al., 2002; Leggat, 2007).

In addition to the growing importance of interprofessional approaches, several features underscore the importance of integrating the factor "internationalization" into the design of educational programs. Firstly, the global pool of health care management talent is increasing with professionals crossing national borders and generating global communities of expertise (Frenk et al., 2010). 
There is an increase in the migration of professionals (to wealthier countries such as USA, Canada, but also within the European Union), also related to chronic shortages of experts in those countries (Pang, 2002; Patel, 2003; Plotnikova, 2012; Wismar, 2011b). Secondly, in addition to increasing mobility, an acceleration of all types of health-related flows can be observed manifesting through international accreditation, financing models, trade in health services and also patient movements as in the case of cross-border health care or medical tourism. Also more and more medical services such as diagnostic tests or reading of electrocardiagrams or radiographs are moving across national borders (Kluge, 2011). This trade in services might further intensify competition between professionals of different countries that are similarly skilled but operate with different cost structures (Frenk et al., 2010). Thirdly, globalization is also having an impact on professional education with some schools moving abroad to establish affiliated campuses in emerging economies. Up to date, there are different variants of these brand-name professional schools such as export of only technical expertise, joint ventures or even overseas campuses. However, the sustainability and implications of those developments are still uncertain (Frenk et al., 2010).

Through organizing and participating in an international and interprofessional summer school, students and lecturers as well as the related higher education institutions (HEls) benefit. Firstly, the course provided an excellent opportunity to strengthen cooperation among the participating HEls through students and lecturers exchange. The HEls were going to cooperate not only in summer school, but as a further level of cooperation between the partners, the joint degree master's program "European Master in Health Economics and Management" (Eu-HEM) has been established, starting in October 2015. Secondly, although the topic of cross border care and patient mobility only recently arrives in the curricula of health management programs, the European and international health community considers these developments as priority areas within the next years (Wismar et al., 2011a). For this reason, health care managers require training and added expertise to be able to adapt to the changing work environment. The summer school dealt with this topic and encouraged the respective institutions to do further research and convey this knowledge through implementation in curricula. Thirdly, by involving local hospitals, health insurance organizations and IT companies which are confronted in their professional everyday life with the theme of the summer school (European Patient Mobility), impulses for increasing cooperation between health care management education and enterprises were provided. For example, the Veneto Region has established specific agreements with seven German health insurance companies on health services provided for visitors travelling to the region or long term residents. During summer school the key characteristics of these agreements (e.g. e-billing for health services) have been outlined and students received a direct insight into the process of reimbursement and invoicing at the local hospitals. Lastly, the project also facilitated the development of innovative practices in education and training at the tertiary level, and their transfer from one participating country to others. The summer school allowed academic staff to exchange experience on teaching methodology as well as on contents and to disseminate knowledge in a broader area.

Through this multi-dimensional approach the summer school contributed to the process of students to become trained academics, emphasizing academic education on the interface of development and application of knowledge, and working from an interdisciplinary approach. By working on individual and group assignments in a real-life setting and by being exposed to experts in the field, students were able to prove their leadership skills, show respectful interaction with their colleagues, improve their knowledge in a specific thematic area, and develop common goals and strategies to 
work collaboratively in diverse teams. Participating students were hence given the opportunity to acquire valuable skills and competencies which are required by future health care managers as stated earlier in this paper.

In addition to the use of various teaching methods a special focus has been laid on problem-based learning, a student-centered pedagogy in which students learn about a subject in the context of complex, multifaceted, and realistic problems. The goals of this approach were to help the students develop flexible knowledge, effective problem solving skills, self-directed learning, effective collaboration skills and intrinsic motivation. It further provided the lecturers of the different institutions with an excellent interdisciplinary framework for cooperation.

Although there might be some challenges for repeating the concept of the summer school in a regular university setting, especially when considering its intensity (Larsen et al., 2009), we believe that it is important to recreate a learner-centered, open-learning environment, offering a multidisciplinary and intercultural context, with real world assignments, and providing students with easy access to skills, knowledge, and experience shared by teachers, experts and peers.

Nevertheless for future summer schools with similar learning goals there are some suggestions for improvement. The main aims of the summer school have been to prepare future health care managers for an interprofessional and international working environment and to further develop their teamwork skills using a problem-based learning approach in the area of cross border health care. But to draw conclusions if those aims have been achieved based on an relatively simple evaluation approach (as well as on personal discussions among the involved lecturers, health care professionals and industrial experts) might be far-fetched. A more elaborated evaluation of the learning goals for example by using valid and reliable instruments such as the Readiness for Interprofessional Learning Scale (Reid et al., 2006), the Interdisciplinary Education Perception Scale (Luecht et al., 1990), the Team Learning and Psychological Safety scale (Edmondson 1999), or the Intercultural Development Inventory (Hammer et al., 2003) might produce more reliable results.

\section{Conclusion}

Internationalisation and interprofessional cooperation are central to health care in the 21 st century. For health care managers, policy analysts and academic researchers, knowledge of multiple relevant disciplines and an international view and network are key to understanding and solving the problems that health care systems and health care services are facing. The example of a summer school on cross-border health care presented in this article shows how international, interprofessional (and related to that in particularly soft skills) can be integrated into a two-week intensive educational activity and how all stakeholders involved can benefit from a sustainable cooperation between different European higher education institutions.

\section{References}

Aerden, A., Decker, F. de, Divis, J., Frederiks, M. and Wit, H. de (2013), "Assessing the internationalisation of degree programmes: experiences from a Dutch-Flemish pilot certifying internationalisation", Compare: A Journal of Comparative and International Education, Vol. 43 No. 1, pp. 56-78.

Barr H, Koppel I, Reeves S, Hammick M, Freeth D. (2005), Effective interprofessional education: argument, assumption and evidence, Blackwell Publishing, Oxford. 
Berwick, D.M. (2002), "A user's manual for the IOM's 'Quality Chasm' report”, Health affairs (Project Hope), Vol. 21 No. 3, pp. 80-90.

Brandenburg, U., \& Federkeil, G. (2007), How to Measure Internationality and Internationalisation of Higher Education Institutions!: Indicators and Key Figures.

Bridges, D.R., Davidson, R.A., Odegard, P.S., Maki, I.V. and Tomkowiak, J. (2011), "Interprofessional collaboration: three best practice models of interprofessional education", Medical education online, Vol. 16.

Busse, R. and Schlette, S. (2004), Im Blickpunkt: Gesundheitspolitik und Alter, Arzneimittelpolitik, Fachkräfteentwicklung, Gesundheitspolitik in Industrieländern, Vol. 2, Verl. Bertelsmann-Stiftung, Gütersloh.

Calhoun, J. G., Vincent, E. T., Calhoun, G. L., \& Brandsen, L. E. (2008), "Why competencies in graduate health management and policy education?", Journal of Health Administration Education, 25(1), pp. 1735.

Careum (2013), Umrisse einer neuen Gesundheitsbildungspolitik (Outlines of a new health education policy) - careum working paper 7, St. Gallen.

Cassidy, S. (2004), "Learning Styles: An overview of theories, models, and measures", Educational Psychology, Vol. 24 No. 4, pp. 419-444.

Chamberlain-Salaun, J., Mills, J. and Usher, K. (2013), "Terminology used to describe health care teams: an integrative review of the literature", Journal of multidisciplinary healthcare, Vol. 6, pp. 65-74.

Clements, D., Dault, M. and Priest, A. (2007), "Effective teamwork in healthcare: research and reality", HealthcarePapers, 7 Spec No, pp. 26-34.

Craddock D, O'Halloran C, Borthwick A, McPherson K. (2006), "Interprofessional education in health and social care: fashion or informed practice?", Learn Health Soc Care, No. 5, pp. 220-242.

Edmondson, A. (1999), "Psychological Safety and Learning Behavior in Work Teams", Administrative Science Quarterly, Vol. 44 No. 2, p. 350.

Edmondson, A.C., Bohmer, R.M. and Pisano, G.P. (2001), "Disrupted Routines: Team Learning and New Technology Implementation in Hospitals", Administrative Science Quarterly, Vol. 46 No. 4, p. 685.

European Commission (2009), ECTS User's Guide, Luxembourg.

European Commission (04.2011), Directive 2011/24/EU of the European Parliament and of the Council of 9 March 2011 on the application of patients' rights in cross-border healthcare: OJ L 88.

European Commission - Bologna Secretariat (1999), Bologna Declaration of 19 June 1999.

Farmer, E.A., Beard, J.D., Dauphinee, W.D., LaDuca, T. and Mann, K.V. (2002), "Assessing the performance of doctors in teams and systems", Medical education, Vol. 36 No. 10, pp. 942-948.

Ferlie, E.B. and Shortell, S.M. (2001), "Improving the quality of health care in the United Kingdom and the United States: a framework for change", The Milbank quarterly, Vol. 79 No. 2, pp. 281-315.

Frenk A., Bhutta, Z.A., Chen, L., Cohen, J., Crisp, N., Evans, T., Fineberg, H., Frenk, J., Garcia, P., Horton, R., Ke, Y., Kelley, P., Kistnasamy, B., Meleis, A., Naylor, D., Pablos-Mendez, A., Reddy, S., Scrimshaw, S., Sepulveda, J., Serwadda, D. and Zurayk, H. (2010), "Education of health professionals for the 21st century: a global independent Commission", The Lancet, Vol. 375 No. 9721, pp. 11371138. 
Freshman, B. and Rubino, L. (2002), "Emotional intelligence: a core competency for health care administrators", The health care manager, Vol. 20 No. 4, pp. 1-9.

Garman, A.N. and Johnson, M.P. (2006), "Leadership competencies: an introduction", Journal of healthcare management / American College of Healthcare Executives, Vol. 51 No. 1, pp. 13-17.

Gemperli, A., Sottas, B. and Stucki, G. (2014), "Health professionals for the future", BMC Health Services Research, Vol. 14 No. Suppl 2, pp. P43.

Goleman, D. (2000), “Leadership that gets results", Harvard business review, No. 78(2), pp. 78-93.

Hagopian, A., Thompson, M.J., Fordyce, M., Johnson, K.E. and Hart, L.G. (2004), "The migration of physicians from sub-Saharan Africa to the United States of America: measures of the African brain drain", Human resources for health, Vol. 2 No. 1, p. 17.

Haidet, P., O'Malley, K. J., \& Richards, B. (2002), "An initial experience with "team learning" in medical education", Academic Medicine, No. 77(1), pp. 40-44.

Hammer, M.R., Bennett, M.J. and Wiseman, R. (2003), "Measuring intercultural sensitivity: The intercultural development inventory", International Journal of Intercultural Relations, Vol. 27 No. 4, pp. 421-443.

Hudak, R.P., Brooke, P.P. and Finstuen, K. (2000), "Identifying management competencies for health care executives: review of a series of Delphi studies", The Journal of health administration education, Vol. 18 No. 2, pp. 213-43; discussion 244-9.

Karanikolos, M., Mladovsky, P., Cylus, J., Thomson, S., Basu, S., Stuckler, D., Mackenbach, J.P. and McKee, M. (2013), "Financial crisis, austerity, and health in Europe", The Lancet, Vol. 381 No. 9874, pp. 13231331.

Karoly, L. A., \& Panis, C. W. (2004), The 21st century at work: Forces shaping the future workforce and workplace in the United States.

Kifmann, M. and Wagner, C. (2014), "Implications of the EU Patients' Rights Directive in Cross-Border Healthcare on the German Sickness Fund System", in Levaggi, R. and Montefiori, M. (Eds.), Health Care Provision and Patient Mobility, Developments in health economics and public policy, Vol. 12, Springer Milan, Milano, pp. 49-66.

Kleinert, S. and Horton, R. (2013), "Health in Europe—successes, failures, and new challenges", The Lancet, Vol. 381 No. 9872, pp. 1073-1074.

Kluge, E.-H.W. (2011), "Ethical and legal challenges for health telematics in a global world: telehealth and the technological imperative", International journal of medical informatics, Vol. 80 No. 2, pp. e1-5.

Knight, D., Durham, C.C. and Locke, E.A. (2001), "THE RELATIONSHIP OF TEAM GOALS, INCENTIVES, AND EFFICACY TO STRATEGIC RISK, TACTICAL IMPLEMENTATION, AND PERFORMANCE”, Academy of Management Journal, Vol. 44 No. 2, pp. 326-338.

Knight, J. (2008), Higher education in turmoil. The Changing World of Internationalisation, Sense Publishers, Rotterdam.

Kolb, A.Y. and Kolb, D.A. (2005), "Learning Styles and Learning Spaces: Enhancing Experiential Learning in Higher Education", Academy of Management Learning \& Education, Vol. 4 No. 2, pp. 193-212.

Larsen, P.G., Fernandes, J.M., Habel, J., Lehrskov, H., Vos, R., Wallington, O. and Zidek, J. (2009), "A multidisciplinary engineering summer school in an industrial setting", European Journal of Engineering Education, No. 2, pp. 511-526.

Leggat, S.G. (2007), "Effective healthcare teams require effective team members: defining teamwork competencies", BMC health services research, Vol. 7, p. 17. 
Levaggi, R. and Montefiori, M. (Eds.) (2014), Health Care Provision and Patient Mobility, Developments in health economics and public policy, Springer Milan, Milano.

Luecht, R.M., Madsen, M.K., Taugher, M.P. and Petterson, B.J. (1990), "Assessing professional perceptions: design and validation of an Interdisciplinary Education Perception Scale", Journal of allied health, Vol. 19 No. 2, pp. 181-191.

MacKinnon, N.J., Chow, C., Kennedy, P.L., Persaud, D.D., Metge, C.J. and Sketris, I. (2004), "Management Competencies for Canadian Health Executives: Views from the Field", Healthcare Management Forum, Vol. 17 No. 4, pp. 15-20.

MacKinnon, N. J., Chow, C., Kennedy, P. L., Persaud, D. D., Metge, C. J., \& Sketris, I. (2005), "Management competencies for Canadian health executives: views from the field", Healthcare Management Forum, Vol. 17 No. 4, pp. 15-20.

Mahler, C., Gutmann, T., Karstens, S. and Joos, S. (2014), "Terminology for interprofessional collaboration: definition and current practice", GMS Zeitschrift für medizinische Ausbildung, Vol. 31 No. 4, pp. Doc40.

Mahon, A. Young, R., "Health care managers as a critical component of the health care workforce", in European Observatory on Health Systems - Human Resources for health in Europe, p. 116.

Maskell, D.L. and Grabau, P.J. (1998), "A multidisciplinary cooperative problem-based learning approach to embedded systems design”, IEEE Transactions on Education, Vol. 41 No. 2, pp. 101-103.

Matta, N. F., \& Ashkenas, R. N. (2003), "Why good projects fail anyway", Harvard business review, 81(9), pp. 109-116.

Mccallin, A. (2001), "Interdisciplinary practice - a matter of teamwork: an integrated literature review", Journal of Clinical Nursing, Vol. 10 No. 4, pp. 419-428.

OECD (2014), Health at a Glance: Europe 2014.

Pang, T. (2002), "Brain drain and health professionals", BMJ, Vol. 324 No. 7336, pp. 499-500.

Patel, V. (2003), "Recruiting doctors from poor countries: the great brain robbery?", BMJ (Clinical research ed.), Vol. 327 No. 7420 , pp. 926-928.

Plotnikova, E.V. (2012), "Cross-border mobility of health professionals: contesting patients' right to health", Social science \& medicine (1982), Vol. 74 No. 1, pp. 20-27.

Pruitt, S.D. and Epping-Jordan, J.E. (2005), "Preparing the 21st century global healthcare workforce", BMJ (Clinical research ed.), Vol. 330 No. 7492, pp. 637-639.

Reeves, S., Zwarenstein, M., Goldman, J., Barr, H., Freeth, D., Hammick, M. and Koppel, I. (2008), "Interprofessional education: effects on professional practice and health care outcomes", The Cochrane database of systematic reviews, No. 1, pp. CD002213.

Reeves, S., Perrier, L., Goldman, J., Della Freeth and Zwarenstein, M. (2013), "Interprofessional education: effects on professional practice and healthcare outcomes (update)", The Cochrane database of systematic reviews, Vol. 3, pp. CD002213.

Reid, R., Bruce, D., Allstaff, K. and McLernon, D. (2006), "Validating the Readiness for Interprofessional Learning Scale (RIPLS) in the postgraduate context: are health care professionals ready for IPL?", Medical education, Vol. 40 No. 5, pp. 415-422.

Rosenbrock, R., \& Gerlinger, T. (2012), Lehrbuch Gesundheitspolitik: eine systematische Einführung, Hans Huber. 
Scaramagli, S., Zanon, D., Ronfini, F., Bertinato, L., \& Toniolo, F. (2006), "Health care for tourists in the Veneto region", Patient Mobility in the European Union, p. 79.

Shewchuk, R.M., O'Connor, S.J. and Fine, D.J. (2005), "Building an understanding of the competencies needed for health administration practice", Journal of healthcare management / American College of Healthcare Executives, Vol. 50 No. 1, pp. 32-47; discussion 48.

Sparks, J.R. and Schenk, J.A. (2001), "Explaining the effects of transformational leadership: an investigation of the effects of higher-order motives in multilevel marketing organizations", Journal of Organizational Behavior, Vol. 22 No. 8, pp. 849-869.

Stefl, M.E. (2008), "Common competencies for all healthcare managers: the Healthcare Leadership Alliance model", Journal of healthcare management / American College of Healthcare Executives, Vol. 53 No. 6, pp. 360-73; discussion 374.

Ulrich, D. and Smallwood, N. (2004), "Capitalizing on capabilities", Harvard business review, Vol. 82 No. 6 , pp. 119-27, 138.

Wake-Dyster, W. (2001), "Designing teams that work”, Australian Health Review, Vol. 24 No. 4, p. 34.

Wass, V., Van der Vleuten, Cees, Shatzer, J. and Jones, R. (2001), "Assessment of clinical competence", The Lancet, Vol. 357 No. 9260, pp. 945-949.

West, M.A., Borrill, C., Dawson, J., Scully, J., Carter, M., Anelay, S., Patterson, M. and Waring, J. (2002), "The link between the management of employees and patient mortality in acute hospitals", The International Journal of Human Resource Management, Vol. 13 No. 8, pp. 1299-1310.

Wismar, M. (2011a), Cross-border health care in the European Union: Mapping and analysing practices and policies, Observatory studies series, Vol. 22, WHO, Regional Office for Europe, Copenhagen.

Wismar, M. (2011b), Health professional mobility and health systems: Evidence from 17 European countries, Observatory studies series, Vol. 23, World Health Organization, on behalf of the European Observatory on Health Systems and Policies, Copenhagen.

Wismar, M., Palm, W., Figueras, J., Ernst, K., \& Van Ginneken, E. (Ed.) (2011), Cross-border health care in the European Union: mapping and analysing practices and policies: European Observatory on Health Systems and Policies Study Series, Vol. 22.

Wit, H. de (Ed.) (2009), Measuring success in the internationalisation of higher education., Brandenburg, Uwe, and Gero Federkeil. How to Measure Internationality and Internationalisation of Higher Education Institutions!: Indicators and Key Figures.

Wit, J. de (2011), "Globalization and Internationalisation of Higher Education", RUSC. Universities and Knowledge Society Journal, Vol. 8 No. 2, p. 77.

Wood, D.F. (2003), "ABC of learning and teaching in medicine: Problem based learning", BMJ, Vol. 326 No. 7384, pp. 328-330.

World Health Organization (2005), Preparing a health care workforce for the 21st century: the challenge of chronic conditions., Geneva.

World Health Organization (2010), Framework for action on interprofessional education and collaborative practice, Geneva.

Xu, D., Sun, B., Wan, X. and Ke, Y. (2010), "Reformation of medical education in China", The Lancet, Vol. 375 No. 9725 , pp. 1502-1504.

Yeatts, D.E. and Seward, R.R. (2000), "Reducing turnover and improving health care in nursing homes: the potential effects of self-managed work teams", The Gerontologist, Vol. 40 No. 3, pp. 358-363. 